\title{
Efeito da Monensina Sódica sobre a Produção e Composição do Leite, a Produção de Mozzarela e o Escore de Condição Corporal de Búfalas Murrah ${ }^{1}$
}

\author{
Cristiana Andrighetto ${ }^{2}$, André Mendes Jorge ${ }^{3}$, Maria Isabel Franchi Vasconcellos Gomes ${ }^{4}$, \\ Amanda Hoch ${ }^{5}$, Adriana Piccinin 6
}

\begin{abstract}
RESUMO - Avaliou-se o efeito da adição de monensina sódica sobre a produção, composição do leite, produção de mozzarela e o escore de condição corporal de búfalas da raça Murrah. O experimento foi conduzido na Área de Produção de Bubalinos da UNESP- FMVZ Botucatu/SP, utilizando-se vinte e quatro búfalas da raça Murrah, submetidas a dois tratamentos, $\mathrm{T}_{1}$ : sem adição de monensina sódica na dieta $\mathrm{T}_{2}$ : adição de $300 \mathrm{mg}$ de monensina sódica por búfala por dia na dieta, durante os primeiros 150 dias de lactação. Os animais receberam dieta composta por silagem de sorgo, capim-elefante e concentrado. Semanalmente, foram anotadas as produções de leite, coletando-se amostras, para a determinação dos teores de proteína, gordura, sólidos totais, e avaliando-se o peso vivo e escore de condição corporal. Foram calculadas as produções de mozzarella, leite (total e média diária), produção de leite corrigida para 270 dias de lactação, produções de proteína e de gordura e relação proteína:gordura. O delineamento experimental foi inteiramente casualizado. Não houve diferenças estatísticas entre os tratamentos para produção média diáriade leite, produção total corrigida para 270 dias, produção de leite no pico da lactação, produção de mozzarella, porcentagens de proteína e sólidos totais, relação proteína:gordura, peso vivo e escore de condição corporal. A monensina influenciou positivamente, com diferenças estatísticas entre os tratamentos na produção diária de proteína $\left(\mathrm{T}_{1}=47,10 \mathrm{~g}, \mathrm{~T}_{2}=162,07 \mathrm{~g}\right)$, gordura $\left(\mathrm{T}_{1}=226,90 \mathrm{~g}, \mathrm{~T}_{2}=259,62 \mathrm{~g}\right)$ e a porcentagem de gordura do leite $\left(\mathrm{T}_{1}=5,41 \%, \mathrm{~T}_{2}=5,84 \%\right)$.
\end{abstract}

Palavras-chave: búfalos de rio, gordura, ionóforo, lactação, proteína

\section{Effect of Monensin on Milk Production and Composition, Production of Mozzarela Cheese and Body Condition Score of Murrah Buffalo Cows}

\begin{abstract}
The effect of monensin on milk production, milk composition and body condition score of buffaloes cows in early lactation was evaluated. Twenty four Murrah buffalo cows were submitted to two treatments $\mathrm{T}_{1}\left(0 \mathrm{mg}\right.$ of monensin/buffalo cow/day) $\mathrm{T}_{2}$ ( $300 \mathrm{mg}$ of monensin/buffalo cow/day) evaluated during the 150 first days of lactation. The total ration was composed by sorghum silage, elephant grass, and concentrate. The effect of monensin on milk production, milk composition and body condition score of buffaloes cows in early lactation was evaluated. Weekly, data on milk production recorde, and milk samples were collected, for determination of protein, fat and total solids analysis were measured. The buffaloes cows were also evaluated for live weight and the body condition score. Mozzarela production, milk production (total and daily mean), milk production corrected for 270 days of lactation, protein and fat productions and protein: fat ratio were recorded. A completely randomized experimental design was used. There was no differences between treatments for daily milk and for total milk production corrected for 270 days, milk production at the peak of lactation, mozzarela production, protein and total solids percentage, protein:fat ratio, live weight and body condition score. Monensin influenced positively, with differences between treatments for daily protein $\left(\mathrm{T}_{1}=147.10 \mathrm{~g}, \mathrm{~T}_{2}=162.07 \mathrm{~g}\right)$ and fat production, $\left(\mathrm{T}_{1}=226.90 \mathrm{~g}, \mathrm{~T}_{2}=259.62 \mathrm{~g}\right)$ and fat percentage $\left(\mathrm{T}_{1}=5.41 \%, \mathrm{~T}_{2}=5.84 \%\right)$.
\end{abstract}

Key Words: ionophor, fat, lactation, protein, water buffalo

\section{Introduçãa}

O tamanho do rebanho bubalino brasileiro é de 1.150 .052 cabeças, com crescimento anual de $12,8 \%$ nos últimos 10 anos. Na região Norte, concentra-se a maior parte, seguida das regiões Sul e Sudeste (Anualpec, 2003). Na América do Sul, o Brasil é o detentor do maior rebanho, seguido da Venezuela e da Argentina (Valle, 1999). Os bubalinos são considerados uma boa opção para a pecuária leiteira visto seu potencial para produção de leite em várias condições ambientais.

Em virtude das características físico-químicas particulares do leite de búfala, como, por exemplo, os

\footnotetext{
${ }^{1}$ Parte da dissertação da primeira autora apresentada ao Programa de Pós Graduação em Zootecnia pela FMVZ/UNESP-Botucatu-SP. Bolsa de estudos da CAPES.

2 Doutoranda em Zootecnia pela FMVZ/UNESP/Botucatu-SP (andrighetto@fca.unesp.br).

3 Prof. Dr. do DPEA/FMVZ/UNESP-Botucatu-SP. Pesquisador CNPq (jorgeam@fca.unesp.br).

4 Profa Dra do Departamento de Gestão e Tecnologia Agroindustrial, FCA/UNESP-Botucatu-SP.

5 Zootecnista.

6 Doutoranda em Ciências Biológicas pelo IBB/UNESP-Botucatu -SP.
} 
teores de sólidos totais, de gordura e de caseína (41,1; 88,$5 ; 47,7 \%$ superiores, respectivamente, ao do leite de vaca), sua industrialização tem gerado produtos diferenciados, como mozzarela, provolone e ricota, entre outros, que têm recebido remuneração superior à dos produtos oriundos do leite bovino (Jorge et al., 2002).

Outra vantagem do leite de búfala é o maior rendimento na fabricação de derivados, por apresentar elevados teores de proteína, gordura e sólidos totais. Com o crescimento desse setor, há necessidade de estudos de novas alternativas para melhorar a produção leiteira das búfalas.

Os ionóforos - como a monensina sódica, por exemplo - são aditivos com capacidade de melhorar o desempenho animal e sua adição na dieta de vacas em lactação pode trazer muitos benefícios, como o aumento da produção de leite (Duffield \& Bagg, 2000).

A monensina, quando adicionada na alimentação de bubalinos, apresenta redução na produção de metano (Barman et al., 2001) e de amônia e na população de protozoários, além de ocasionar aumento na produção de propionato ruminal (Badway et al., 1996).

Estudos indicam que a monensina sódica, quando administrada oralmente, é absorvida rapidamente, metabolizada e eliminada nas fezes, não se acumulando nos tecidos dos animais. Dohono (1984), estudando o efeito da adição de monensina na alimentação animal, observou que, quando frangos e bovinos foram alimentados com dosagens recomendadas, a monensina não foi detectada (quantidades menores que $0,05 \mathrm{ppm}$ ) nos tecidos. Em novilhas leiteiras que receberam 300 $\mathrm{mg}$ de monensina por dia durante 4, 5 e 16 dias antes da parição, foram coletadas amostras de colostro durante as primeiras 72 horas de lactação e observouse que nenhuma amostra de colostro apresentou mais que 0,023 ppm deste ionóforo.

Ruiz et al. (2001) utilizaram a monensina na alimentação de vacas Holandesas, em dieta à base de forragem fresca, e observaram aumento de 6,5\% na produção de leite, $4,6 \%$ na produção de gordura e 4,7\% na produção de proteína, havendo, porém, redução de 0,12 unidades percentuais na porcentagem de gordura.

Resultados semelhantes foram encontrados por Hayes et al. (1996), ao avaliarem o efeito da monensina em vacas em pastejo. A suplementação com monensina provocou aumento nas produções de leite (1,38 litros de leite/animal/dia), de proteína $(0,03 \mathrm{~kg} / \mathrm{dia})$ e de gordura $(0,02 \mathrm{~kg} / \mathrm{dia})$, mas essas diferenças foram significativas somente para a produção de leite.
Entretanto, Vallimont et al. (2001) não observaram diferenças na produção de leite quando vacas, no início da lactação, foram suplementadas com monensina sódica. Resultados similares foram reportados por Ramanzin et al. (1997), quando pesquisaram o efeito da monensina em vacas consumindo dietas contendo relação volumoso:concentrado de 70:30.

A mudança no peso corporal durante o início da lactação exerce grande influência na produção de leite e na reprodução de búfalas (Kar \& Sengupta, 1984). Neste período, as búfalas encontram-se com balanço energético negativo, ou seja, não ingerem toda a energia necessária para satisfazer os requerimentos para manutenção e produção de leite (Rosi et al., 1997).

Estudos têm comprovado que a monensina administrada no início da lactação tem efeito positivo no metabolismo energético, melhorando a condição corporal dos animais (Stephenson et al., 1997).

Van Der Merwe et al. (2001) conduziram um experimento utilizando vacas de leite criadas em pastejo e constataram que os animais que receberam monensina na dieta apresentaram maior ganho de peso que o grupo que aqueles que não receberam monensina. No final do experimento, o grupo suplementado apresentou melhor escore de condição corporal do que o grupo controle.

Duffield et al. (1998) observaram menor perda de peso e, conseqüentemente, melhor condição corporal de vacas tratadas com monensina durante o período pós-parto, ao passo que Vallimont et al. (2001) não registraram diferenças no escore de condição corporal em vacas leiteiras tratadas com monensina. Resultados semelhantes foram encontrados por Ramanzin et al. (1997), ao fornecerem dietas com alta concentração de forragem.

Hergazy (1997) constatou que búfalas leiteiras suplementadas com monensina apresentaram melhor escore de condição corporal na parição e na próxima concepção, indicando que a monensina pode ser um aditivo vantajoso na produção de bubalinos.

Existem poucos estudos sobre o efeito de ionóforos na alimentação de búfalas em lactação; no Brasil, não foi encontrado nenhuma pesquisa avaliando o efeito de ionóforos na alimentação de búfalas em lactação. Este trabalho foi conduzido para avaliar o efeito de monensina sódica sobre alguns parâmetros produtivos de búfalas Murrah no início da lactação. 


\section{Material e Métodos}

O presente experimento foi realizado na Área de Produção de Bubalinos do Departamento de Produção e Exploração Animal da Faculdade de Medicina Veterinária e Zootecnia, Unesp, no município de Botucatu/SP, cujas coordenadas geográficas são latitude sul $22^{\circ} 51^{\prime}$ e longitude oeste $48^{\circ} 26^{\prime}$, altitude média de $800 \mathrm{~m}$ sobre nível do mar, temperatura média anual de $20,2^{\circ} \mathrm{C}$ e precipitação média anual de $1464 \mathrm{~mm}$.

Foram utilizadas 24 búfalas da raça Murrah em lactação, submetidas ao experimento à medida que foram parindo, utilizando-se para o período experimental os primeiros 150 dias da lactação. Os partos foram concentrados nos meses de março, abril e maio de 2002, período em que as búfalas permaneceram em quatro baias coletivas com área total de $90 \mathrm{~m}^{2}$, dos quais $45 \mathrm{~m}^{2}$ eram cobertos com telha francesa e dispunham de cocho de concreto e bebedouro.

As búfalas receberam dieta balanceada para produção de $4 \mathrm{~kg}$ de leite com $7 \%$ de gordura, de acordo com a recomendação de Kearl (1982). A alimentação foi composta por capim-elefante (Pennisetum purpureum, Schum) picado, cortado aos 90 dias de idade e fornecido nos três primeiros meses de experimento, e silagem de sorgo (Sorghum bicolor (L.) Moench.), fornecida após a partir desse período. Foi utilizada relação de $70 \%$ de volumoso e $30 \%$ de concentrado.

O concentrado fornecido foi composto de $49 \%$ de milho desintegrado, $28 \%$ de farelo de algodão, $11 \%$ de farelo de trigo e $2,75 \%$ de mistura mineral. Foram realizadas análises semanais de matéria seca (MS), proteína bruta $(\mathrm{PB})$, extrato etéreo $(\mathrm{EE})$, matéria mineral (MM) e fibra em detergente neutro (FDN) do capim-elefante, da silagem de sorgo e da ração, de acordo com Association of Official Analytical Chemistis - AOAC (1990) e Van Soest et al. (1991). As análises foram realizadas no Laboratório de Bromatologia do Departamento de Nutrição e Melhoramento Animal da Unesp-Campus Botucatu-SP da Faculdade de Medicina Veterinária e Zootecnia e a composição química dos volumosos e do concentrado encontra-se na Tabela 1.

A alimentação foi fornecida sempre após a ordenha e as sobras que representaram de $5 \%$ a $10 \%$ do alimento fornecido, foram pesadas, monitorando-se o consumo diário de matéria seca, expresso em porcentagem do peso vivo.

Os animais foram divididos em dois grupos homogêneos, conforme a produção de leite, ordem de lactação (não havendo animais com diferentes ordens de lactação entre os tratamentos) e escore de condição corporal, e receberam os seguintes tratamentos:

T 1 - sem adição de monensina sódica na alimentação (SMon);

T 2 - adição de $300 \mathrm{mg}$ de monensina sódica por búfala por dia (CMon) na dieta.

A fonte de monensina sódica utilizada foi o produto comercial Rumensin ${ }^{\circledR}$ da Eli Lilly do Brasil Divisão Elanco Saúde Animal, adicionado ao concentrado. As búfalas passaram por um período de 10 dias de adaptação ao aditivo, quando receberam $150 \mathrm{mg}$ de monensina por dia, elevando-se após este período, para $300 \mathrm{mg}$ por dia. O registro de dados iniciou-se após o período de adaptação.

Tabela 1 - Composição bromatológica dos volumosos e do concentradom, em percentual da matéria seca Table 1 - Bromatological composition of concentrate in dry matter basis

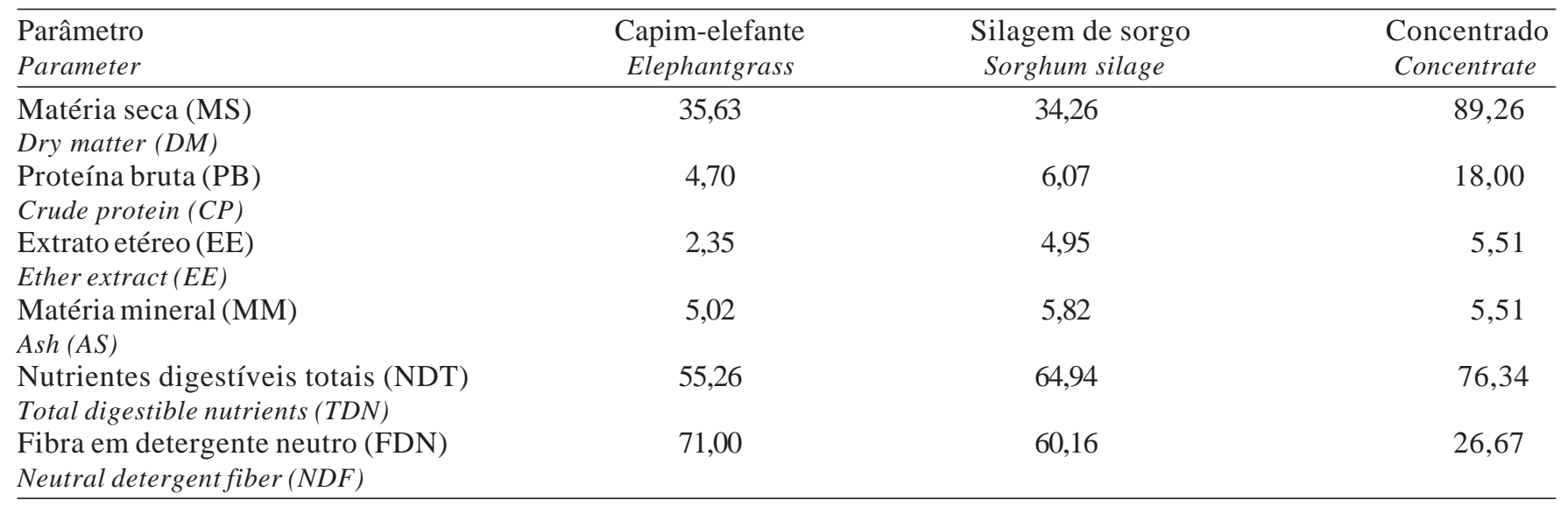


A ordenha foi feita com ordenhadeira mecânica uma vez ao dia e o controle leiteiro foi realizado semanalmente, coletando-se amostras, para as análises de gordura, proteína e sólidos totais. As amostras foram congeladas a $-5^{\circ} \mathrm{C}$, para serem processadas no Departamento de Gestão e Tecnologia Agroindustrial da Faculdade de Ciências Agronômicas - Unesp/ Botucatu, de acordo com as Normas Analíticas do Instituto Adolfo Lutz (1976) e com os procedimentos descritos no Standard Methods for Examination of Dairy Products (1975).

Foram calculadas as produções de gordura e de proteína e a relação proteína:gordura durante o período experimental, estimando-se a produção de mozzarella conforme a fórmula de Altiero et al. (1989):

Mozzarella $(\mathrm{kg})=($ leite, $\mathrm{kg}) *[3,5 *($ proteína,$\%)$ $+1,23 *($ gordura, $\%)-0,88] / 100$

A produção de leite foi corrigida para 270 dias de lactação, multiplicando-se a produção de leite nos 150 dias de lactação pelo fator de correção 1,93084, segundo Tonhati (2001).

As búfalas foram pesadas semanalmente após a ordenha, sem jejum prévio, em balança mecânica com capacidade para $1.500 \mathrm{~kg}$, avaliando-se o Escore de Condição Corporal (ECC) em escala de 1 a 5 (1 = magra e $5=$ gorda), por meio de observações visuais da garupa, lombo e costelas, segundo metodologia preconizada por Perkins et al. (1985).

O delineamento experimental foi inteiramente casualizado. As análises estatísticas foram processadas por intermédio do SAEG (UFV, 1997). Para os parâmetros analisados, foi empregada a comparação das médias pelo o teste Tukey a 5\% de probabilidade, com exceção do escore de condição corporal, para o qual utilizou-se um método não-paramétrico, o teste de Wilconxon.

Para a análise de produção de leite total corrigida para 270 dias de lactação, produção de leite no pico da lactação, produção total de mozzarella, peso e escore de condição corporal, adotou-se o seguinte modelo estatístico:

$$
\mathrm{Y}_{\mathrm{ij}}=\mathrm{m}+\mathrm{T}_{\mathrm{i}}+e_{\mathrm{ij}}
$$

em que: $\mathrm{Y}_{\mathrm{ij}}=$ variável dependente; $\mathrm{m}=$ média geral das observações; $\mathrm{T}_{\mathrm{i}}=$ efeito de tratamento $i$, com $i=1$ e $2 ; e_{\mathrm{ij}}=$ erro aleatório.
Para medida da produção média diária de leite, porcentagem de proteína, gordura e sólidos totais, produção de gordura, proteína, mozzarella diária e relação proteína:gordura, empregou-se o procedimento de parcelas subdivididas do programa SAEG - Sistema para Análise Estatística e Genética (UFV, 1997) de acordo com o modelo estatístico: $\mathrm{Y}_{\mathrm{ijk}}=\mathrm{m}+\mathrm{T}_{\mathrm{i}}+(\mathrm{C} / \mathrm{T})_{\mathrm{ij}}$ $+\mathrm{CO}_{\mathrm{k}}+\left(\mathrm{T}^{*} \mathrm{CO}\right)_{\mathrm{ik}}+\left[(\mathrm{C} / \mathrm{T})^{*} \mathrm{CO}\right]_{\mathrm{ijk}}$, em que: $\mathrm{Y}_{\mathrm{ijk}}=$ variável dependente; $\mathrm{m}=$ média geral das observações; $\mathrm{T}_{\mathrm{i}}=$ efeito de tratamento $i, \operatorname{com} i=1$ e $2 ;(\mathrm{C} / \mathrm{T})_{\mathrm{ij}}$ $=$ efeito da búfala $j$, com $=1,2,3, \ldots 12$ dentro de tratamento $i$ e $j=1,2,3 \ldots 20$, erro A; $\mathrm{CO}_{\mathrm{k}}=$ efeito da coleta $k$, com $k=1,2,3 \ldots 20 ;\left(\mathrm{T}^{*} \mathrm{CO}\right)_{\mathrm{ik}}=$ efeito da interação tratamento $i$ e colheita $k ;(\mathrm{C} / \mathrm{T})^{*} \mathrm{CO}_{\mathrm{ijk}}=$ efeito da interação $(\mathrm{C} / \mathrm{T})_{\mathrm{ij}}$ com coleta $k$, ou erro B. Os dados de produção de leite foram ajustados de acordo com a função gama (Wood, 1967), expressa por: $\mathrm{Y}_{\mathrm{t}}=\mathrm{at}{ }^{\mathrm{b}} \exp (-\mathrm{ct})$, em que: $\mathrm{Y}_{\mathrm{t}}=$ média da produção de leite no tempo $t ; \quad \mathrm{a}=$ constante associada à produção média no início de lactação; $b$ = taxa média de ascensão da produção até atingir produção máxima; $\mathrm{c}=$ taxa média de declínio da produção após atingir o pico, produção máxima e persistência.

Para o ajuste da produção de leite, utilizou-se o método Gauss-Newton do procedimento REGREGN do programa SAEG (UFV, 1997).

A produção no pico de lactação foi definida por: $Y \max =a(b / c)^{b} e^{-b}$, em que: $\mathrm{a}=$ constante associada à produção média no início de lactação; $\mathrm{b}=$ taxa média de ascensão da produção até atingir produção máxima; $\mathrm{c}=$ taxa média de declínio da produção após atingir o pico, produção máxima e persistência. Procedeu-se à análise de regressão para o ajuste dos dados de escore de condição corporal e peso, com a obtenção do coeficiente de determinação $\left(\mathrm{r}^{2}\right)$.

\section{Resultados e Discussão}

O consumo médio estimado de matéria seca dos animais foi de 2,24 e 2,13\% do peso vivo, para os animais dos tratamentos SMon e CMon, respectivamente, que foi próximo ao apresentado por Zicarelli (1999) em búfalas leiteiras alimentadas com dietas contendo proporções de volumoso (2,2 a 2,4\% PV).

$\mathrm{Na}$ Tabela 2, encontra-se a produção média diáriade leite e produções de leite total e corrigida para 270 dias e produção de mozzarela, não havendo 
diferença significativa para os parâmetros avaliados. A produção de leite corrigida para 270 dias foi de $1.228,06 \mathrm{~kg}$ para o grupo controle e de $1.328,65 \mathrm{~kg}$, para o grupo suplementado com monensina, próxima à encontrada por Tonhati et al. (2000), que observaram produção de leite de $1.259,47 \mathrm{~kg}$ ajustada para 270 dias de lactação em búfalas Murrah e suas mestiças pertencentes a rebanhos bubalinos do estado de São Paulo. O coeficiente de variação para a produção de leite corrigida para 270 dias neste estudo $(22,23 \%)$ foi superior ao valor de $17,5 \%$, encontrado por Faria (1997), e inferior ao de 41,53\%, registrado por Tonhati (2000).

Os dados obtidos neste estudo para produção estimada de mozzarella nos dois tratamentos foram inferiores aos relatados por Rosati \& Vanfleck (2002), que observaram produção de 589,1 $\pm 125,4 \mathrm{~kg}$ durante a lactação de búfalas italianas, porém, próximos aos encontrados por Andrighetto et al. (2003), de 184,07 kg durante a lactação de búfalas da raça Murrah.

A produção estimada de mozzarella apresentou coeficientes de correlação positivos e significativos $(\mathrm{P}<0,01)$ de 0,$91 ; 0,93$ e 0,97 para as produções de leite, gordura e proteína, respectivamente. A produção de mozzarella não apresentou diferenças estatísticas entre os tratamentos $(\mathrm{P}>0,05)$, porém houve aumento de $16,42 \mathrm{~kg}$ por animal na produção de mozzarela de búfalas suplementadas com monensina nos primeiros 150 dias de lactação, o que, de certa forma, tem significado econômico.
Consta na Figura 1 a produção de leite real observada nos controles semanais. Os dois tratamentos ocasionaram comportamentos semelhantes para produção de leite durante o período experimental, porém o tratamento 2 (Cmon) proporcionou produção de leite superior ao tratamento 1 (Smon) durante toda a lactação, não havendo, porém, diferenças significativas $(\mathrm{P}>0,05)$ para a produção de leite total, produção total ajustada para 270 dias de lactação, produção de leite no pico da lactação e produção média diária de leite (Tabela 2).

Outros autores também não encontraram efeito da monensina sódica na produção de leite de bovinos (Sauer et al., 1989; Ramanzim et al., 1997; Beckett et al., 1998; Vallimont et al., 2001). Entretanto, Campos et al. (1995) e Ruiz et al. (2001) observaram produções de leite superiores e significativas quando vacas Holandesas foram tratadas com monensina.

Na Figura 2, as curvas de lactação foram ajustadas pela função gama e apresentaram $\mathrm{r}^{2}$ de 0,54 e 0,55 para o tratamento 1 e tratamento 2 , respectivamente, semelhantes aos obtidos por Gaona et al. (1985), de 0,25 a 0,52 nas curvas de lactação de búfalas mestiças e da raça Mediterrâneo, também ajustadas pela função gama.

Os dados da composição do leite de búfalas Murrah sem e com adição de monensina encontram-se na Tabela 3. O tratamento com monensina proporcionou diferenças $(\mathrm{P}<0,05)$ nas produções de gordura e proteína e na porcentagem de gordura superiores ao tratamento controle, porém não afetou $(\mathrm{P}>0,05)$ a porcentagem de proteína e de sólidos totais.

Tabela 2 - Produção de leite total, no pico de lactação, corrigida (270 dias) e produção de mozzarella de búfalas Murrah nos primeiros 150 dias de lactação, recebendo ou não monensina na dieta

Table 2 - Total milk production, o peak of lactation, milk corrected (270 days), and mozzarella from Murrah buffalo cows during the first 150 days of lactation, without or with monensin addition on feed

\begin{tabular}{|c|c|c|c|}
\hline \multirow[t]{2}{*}{$\begin{array}{l}\text { Parâmetro } \\
\text { Parameter }\end{array}$} & \multicolumn{2}{|c|}{$\begin{array}{l}\text { Tratamento (mg de monensina/búfala/dia) } \\
\text { Treatment (mg monensin/buffalo cow/day) }\end{array}$} & \multirow[b]{2}{*}{$\mathrm{CV}(\%)$} \\
\hline & $0 \mathrm{mg}$ & $300 \mathrm{mg}$ & \\
\hline $\begin{array}{l}\text { Produção de leite }(\mathrm{kg} / \mathrm{dia}) \\
\text { Milk production (kg/day) }\end{array}$ & $4,23^{\mathrm{a}}$ & $4,46^{\mathrm{a}}$ & 18,49 \\
\hline $\begin{array}{l}\text { Produção total de leite }(\mathrm{kg}) \\
\text { Total milk production }(\mathrm{kg})\end{array}$ & $582,20^{\mathrm{a}}$ & $629,89^{a}$ & 22,23 \\
\hline $\begin{array}{l}\text { Produção de leite no pico da lactação }(\mathrm{kg}) \\
\text { Milk production lactation peak }(\mathrm{kg})\end{array}$ & $4,72^{\mathrm{a}}$ & $5,11^{\mathrm{a}}$ & 23,33 \\
\hline $\begin{array}{l}\text { Produção de leite corrigida } 270 \text { dias }(\mathrm{kg}) \\
\text { Milk production corrected } 270 \text { days }(\mathrm{kg})\end{array}$ & $1228,06^{\mathrm{a}}$ & $1328,65^{\mathrm{a}}$ & 22,23 \\
\hline $\begin{array}{l}\text { Produção de mozzarella }(\mathrm{kg} / \mathrm{dia}) \\
\text { Mozzarella production ( } \mathrm{kg} / \text { day })\end{array}$ & $0,76^{\mathrm{a}}$ & $0,84^{\mathrm{a}}$ & 22,74 \\
\hline $\begin{array}{l}\text { Produção total de mozzarella }(\mathrm{kg}) \\
\text { Total mozzarella production }(\mathrm{kg})\end{array}$ & $104,28^{\mathrm{a}}$ & $120,70^{\mathrm{a}}$ & 22,69 \\
\hline
\end{tabular}

Médias seguidas pelas mesmas letras não diferem $(P<0,05)$ pelo teste Tukey.

Means followed by same letters did not differ $(P<.05)$ by Tukey test. 
Dados da literatura confirmam os resultados obtidos deste estudo, indicando aumento da produção de proteína e de gordura do leite de vacas que receberam monensina na dieta (Hayes et al., 1996; Ramanzim et al., 1997; Ruiz et al., 2001). Para a porcentagem de sólidos totais (Tabela 3), os resultados estão de acordo com a literatura, visto que Lean et al. (1994) e Lemenager et al. (1978) também não obtiveram diferenças estatísticas quando vacas leiteiras foram suplementadas com monensina.

Nesta pesquisa, a porcentagem de gordura foi superior $(\mathrm{P}<0,05)$ no grupo tratado com monensina. Entretanto, na literatura, os trabalhos sugerem redução ou não-alteração destes valores, uma vez que a monensina diminui a produção de ácido acético, precursor da gordura do leite, e aumenta a produção de ácido propiônico no rúmen, de modo que tende a reduzir o teor de gordura do leite, o que não foi observado neste ensaio (Van Der Werf et al., 1998; Duffield \& Bagg, 2000).

De acordo com Ramanzin et al. (1997), a redução na proporção molar de ácido acético e o aumento do propiônico tem sido mais efetiva em dietas com alta proporção de concentrado, ao passo que, em dietas com altas proporções de forragem, a quantidade de ácido acético não apresenta redução e a de ácido propiônico tem aumento pequeno (Harmon et al., 1993).

Nas Tabelas 4 e 5, são apresentados o peso vivo médio das búfalas e o escore de condição corporal (ECC) durante o período experimental. Não houve diferença $(\mathrm{P}>0,05)$ para as duas variáveis analisadas.

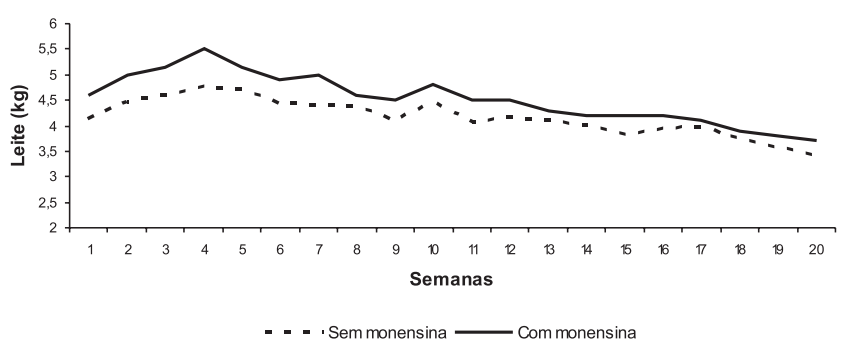

Figura 1 - Produção de leite de búfalas Murrah observada nos primeiros 150 dias de lactação, recebendo ou não monensina na dieta.

Figure 1 - Milk production from Murrah buffalo cows during the first 150 days of lactation without or with monensin addition on feed.
O resultado obtido para ECC neste experimento foi semelhante ao encontrado por Van der Merwe et al. (2001), ao avaliarem o efeito da monensina sódica na dieta de vacas em lactação sob pastejo. Esses autores relataram que o ECC, apesar de não-significativo, foi superior nos animais suplementados, e que o ganho de peso no período experimental foi superior nas vacas alimentadas com monensina.

Ramanzin et al. (1997) também observaram efeito positivo, porém não-significativo, da monensina em escore de condição corporal de animais alimentados com alta proporção de forragem na dieta. Hayes et al.(1996), ao avaliarem mudanças no peso corporal de vacas de leite em pastejo, não verificaram diferença na perda de peso dos animais suplementados ou não com monensina, ao passo que Duffield et al. (1998) constataram que o tratamento com monensina foi superior àquele sem monensina em vacas leiteiras, quanto à perda de peso no período pós-parto.

No período pós-parto, Sauer et al. (1989) notaram que o grupo de vacas leiteiras que não recebeu monensina apresentou perda de peso de $13,7 \mathrm{~kg}$ a mais que o grupo suplementado, resultado semelhante ao obtido por Campos et al. (1995), que registraram perda de peso de $13,4 \mathrm{~kg}$, no mesmo período, em vacas Holandesas.

A monensina eleva a quantidade de proteína no intestino delgado por meio da redução na degradação de proteína ruminal (Russel \& Strobel, 1989). Desse modo, eleva-se a absorção de aminoácidos no intestino

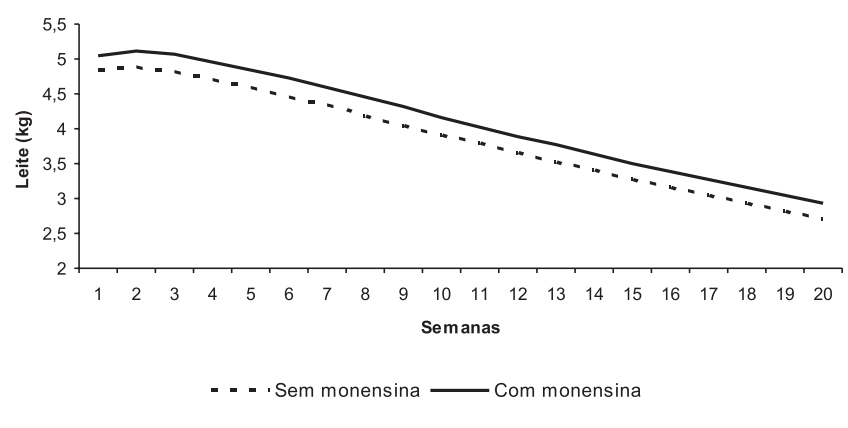

Figura 2 - Produção de leite, ajustada pela função gama, de búfalas Murrah nos primeiros 150 dias de lactação, recebendo ou não monensina na dieta.

Figure 2 - Milk production from Murrah buffalo cows during the first 150 days of lactation adjusted milk production trend, without or with monensin addition on feed. 
Tabela 3 - Produções de gordura e de proteína, porcentagens de gordura, proteína e de sólidos totais e relação proteínagordura de búfalas Murrah nos primeiros 150 dias de lactação, recebendo ou não monensina na dieta

Table 3 - Fat production, protein production, fat percentage, protein percentage, total solids percentage and relation proein:fat from Murrah buffalo cows on first 150 days of lactation with or without monensin addition on feed

\begin{tabular}{|c|c|c|c|}
\hline \multirow[t]{2}{*}{$\begin{array}{l}\text { Parâmetro } \\
\text { Parameter }\end{array}$} & \multicolumn{2}{|c|}{$\begin{array}{l}\text { Tratamento (mg de monensina/búfala/dia) } \\
\text { Treatment (mg monensin/buffalo cow/day) }\end{array}$} & \multirow[b]{2}{*}{$\mathrm{CV}(\%)$} \\
\hline & $0 \mathrm{mg}$ & $300 \mathrm{mg}$ & \\
\hline $\begin{array}{l}\text { Gordura }(\%) \\
\text { Fat }(\%)\end{array}$ & $5,41^{\mathrm{a}}$ & $5,84^{\mathrm{b}}$ & 11,08 \\
\hline $\begin{array}{l}\text { Produção de gordura (kg/dia) } \\
\text { Fat production (kg/day) }\end{array}$ & $0,227^{\mathrm{a}}$ & $0,260^{\mathrm{b}}$ & 17,66 \\
\hline $\begin{array}{l}\text { Proteína }(\%) \\
\text { Protein }(\%)\end{array}$ & $3,51^{\mathrm{a}}$ & $3,66^{\mathrm{a}}$ & 8,77 \\
\hline $\begin{array}{l}\text { Produção de proteína }(\mathrm{kg} / \mathrm{dia}) \\
\text { Protein production }(\mathrm{kg} / \text { day })\end{array}$ & $0,147^{\mathrm{a}}$ & $0,162^{b}$ & 13,31 \\
\hline $\begin{array}{l}\text { Proteína:gordura } \\
\text { Protein:fat }\end{array}$ & $0,66^{\mathrm{a}}$ & $0,63^{\mathrm{a}}$ & 9,85 \\
\hline $\begin{array}{l}\text { Sólidos totais (\%) } \\
\text { Total solids (\%) }\end{array}$ & $14,37^{\mathrm{a}}$ & $14,99^{\mathrm{a}}$ & 8,08 \\
\hline
\end{tabular}

Médias seguidas pelas mesmas letras não diferem $(P<.05)$ pelo teste Tukey.

Means followed by same letters did not differ $(P<.05)$ by Tukey test.

Tabela 4 - Peso médio de búfalas Murrah nos primeiros 150 dias de lactação, recebendo ou não monensina na dieta Table 4 - Weight from Murrah buffalo cows on first 150 days of lactation with or without monensin on feed

\begin{tabular}{|c|c|c|c|}
\hline \multirow[t]{2}{*}{$\begin{array}{l}\text { Parâmetro } \\
\text { Parameter }\end{array}$} & \multicolumn{2}{|c|}{$\begin{array}{l}\text { Tratamento (mg de monensina/búfala/dia) } \\
\text { Treatment (mg monensin/buffalo cow/day) }\end{array}$} & \multirow[b]{2}{*}{$\mathrm{CV}(\%)$} \\
\hline & $0 \mathrm{mg}$ & $300 \mathrm{mg}$ & \\
\hline $\begin{array}{l}\text { Peso inicial }(\mathrm{kg}) \\
\text { Initial weight }(\mathrm{kg})\end{array}$ & $564,50^{\mathrm{a}}$ & $560,66^{\mathrm{a}}$ & 16,82 \\
\hline $\begin{array}{l}\text { Peso final }(\mathrm{kg}) \\
\text { Final weight }(\mathrm{kg})\end{array}$ & $497,16^{\mathrm{a}}$ & $519,33^{\mathrm{a}}$ & 14,00 \\
\hline $\begin{array}{l}\text { Mudança de peso }(\mathrm{kg}) \\
\text { Weight change }(\mathrm{kg})\end{array}$ & $-67,33^{a}$ & $-41,33^{a}$ & 35,74 \\
\hline
\end{tabular}

Médias seguidas pelas mesmas letras não diferem $(P<.05)$ pelo teste Tukey.

Means followed by same letters did not differ $(P<.05)$ by Tukey test.

Tabela 5 - Escore de condição corporal (ECC) de búfalas Murrah nos primeiros 150 dias de lactação, recebendo ou não monensina na dieta

Table 5 - Effect of monensin on body condition score (BCS) from Murrah buffalo cows on first 150 days of lactation with or without monensin on feed

\begin{tabular}{lcc}
\hline Parâmetro & \multicolumn{1}{c}{$\begin{array}{c}\text { Tratamento (mg de monensina/búfala/ dia) } \\
\text { Treatment (mg of monensin/buffalo cow/day) }\end{array}$} \\
\cline { 2 - 3 } & $0 \mathrm{mg}$ & $300 \mathrm{mg}$ \\
\hline $\begin{array}{l}\text { ECC inicial } \\
\text { Initial BCS }\end{array}$ & $3,87^{\mathrm{a}}$ & $3,87^{\mathrm{a}}$ \\
ECC final & $3,13^{\mathrm{a}}$ & $3,22^{\mathrm{a}}$ \\
Final BCS & & \\
$\begin{array}{l}\text { Mudança ECC } \\
\text { Change BCS }\end{array}$ & $-0,73^{\mathrm{a}}$ & $-0,65^{\mathrm{a}}$
\end{tabular}

Médias seguidas pelas mesmas letras não diferem $(P<.05)$ pelo teste Tukey.

Means followed by same letters did not differ $(P<.05)$ by Tukey test. delgado, que serão utilizados para a gliconeogenese, elevando a concentração de glicose sangüínea e reduzindo a mobilização de ácidos graxos. Portanto, a perda de peso no início da lactação pode ser menor em animais suplementados com monensina (Duffield et al., 1998), como foi observado neste estudo.

Nas Figuras 3 e 4, são apresentadas curvas de tendência ajustada do peso e escore de condição corporal das búfalas por tratamento. Segundo Zicarrelli (1999), o período de 110 a 150 dias de lactação é quando as búfalas se encontram em balanço energético negativo. No presente trabalho, os animais tratados com monensina apresentaram menor perda de peso durante os primeiros 150 dias de lactação. 


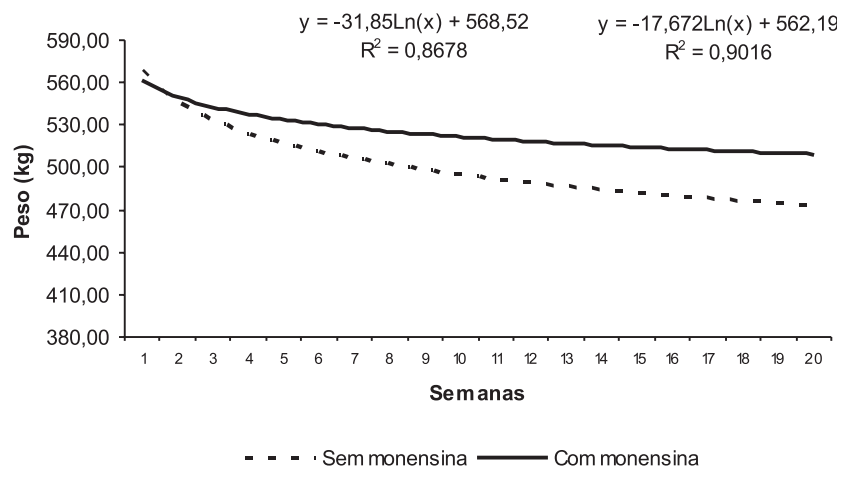

Figura 3 - Peso ajustado de búfalas Murrah nos primeiros 150 dias de lactação, recebendo ou não monensina na dieta.

Figure 3 - Ajusted weight of Murrah buffalo cows during the first 150 days of lactation with or without monensin on feed.

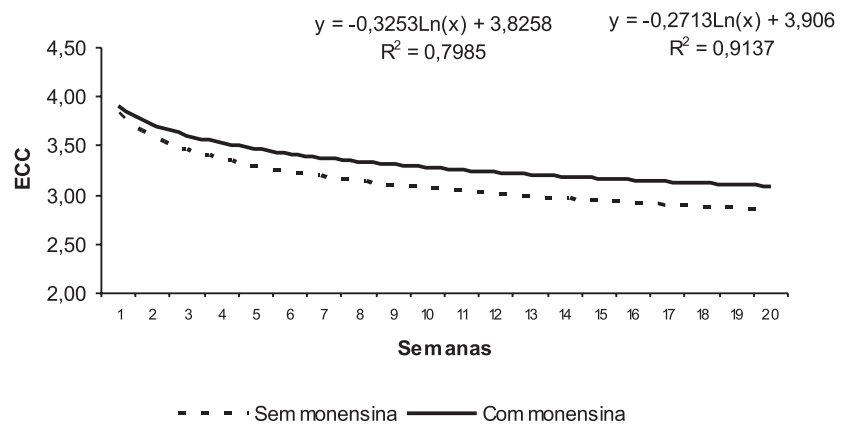

Figura 4 - Escore de condição corporal (ECC) ajustado de búfalas Murrah nos primeiros 150 dias de lactação, recebendo ou não monensina na dieta.

Figure 4 - Ajusted body condition score (BCS) of Murrah buffalo cows during the first 150 days of lactation with or without monensin on feed.

\section{Conclusões}

A monensina sódica não influenciou a produção de leite e de mozzarella, o escore de condição corporal e o peso de búfalas Murrah nos primeiros 150 dias de lactação. Não houve alteração na porcentagem de proteína e de sólidos totais do leite de búfalas suplementadas com monensina.

Por outro lado, a monensina elevou as produções de gordura e de proteína e a porcentagem de gordura do leite de búfalas nos primeiros 150 dias de lactação.

Novos estudos devem ser conduzidos para avaliar a ação da monensina na fermentação ruminal de búfalas leiteiras.

\section{Literatura Citada}

ALTIERO, V.; MOIO, L.; ADDEO, F. Previsione della resa in mozzarela sulla base del contenuto in grasso e proteine del latte di bufala. Science Tecnology Latte, v.40, p.425-433, 1989.

ANDRIGHETTO, C.; JORGE, A.M.; PICCININ, A. et al. Produção de mozzarella e composição do leite de búfalas alimentadas com ionóforos. 2003. In: X REUNIÃO CIENTÍFICA DE CIÊNCIAS AGRÁRIAS DO LAGEADO. Anais... Botucatu-São Paulo. v.10. CD-ROM.

ANUALPEC. Anuário da pecuária brasileira: FNP Consultoria/ Agros Comunicação, São Paulo, SP. 2003, 400p.

ASSOCIATION OF OFFICIAL ANYALITICAL CHEMISTIS - AOAC. 1990. Official methods of analysis. 15.ed. Washington, D.C.: AOAC. 1298p.

BADWAY, S.A.; YONIS, M.; SHALASH, M.R. et al. Monensin effects on rumen metabolic profile, methane production and protozoal population in buffalo heifers. Egyptian Journal of Veterinary Science, v.30, p.49-56, 1996.

BARMAN, K.; MOHINI, M.; SENGHAL, K. Indian Journal of Animal Nutrition, v.18, n.4, p.325-329, 2001.

BECKETT, S.; LEAN. I.; DYSON. R. et al. Effect of monensin on the reproduction, health and milk production. Journal of Dairy Science, v.81, p.1536-1573, 1998.

CAMPOS, O.; RAMOS, A.A.; ESCOBAR, M.J. et al. Avaliação da monensina sódica em vacas leiteiras. Scientia Agrícola, v.52, p.268-273, 1995.

DONOHO, A.L. Biochemical studies on fate of monensin in animals and in the environment. Journal of Animal Science, v. 58, p. 1529-1536, 1984.

DUFFIELD, F.T.; BAGG, R.N. Use of ionofores in lacting dairy cattle: a review. Canadian Veteterinary Journal, v.41, p.388-394, 2000.

DUFFIELD, F.T.; SANDALS, D.; LESLIE, K.E. et al. Effect of prepartum administration of monensin in controled-release capsule on pospartum energy indicators in lactating dairy cows, Journal of Dairy Science, v.81, p.2354-2361, 1998.

FARIA, M.H. Produção de leite e seus constituintes em diferentes grupos genéticos nos bubalinos (Bubalus bubalis). Jaboticabal: Universidade Estadual Paulista. ,1997. 75p. Dissertação (Mestrado em Zootecnia)-Universidade Estadual Paulista. Faculdade de Ciências Agrárias e Veterinárias, 1997

GAONA, J.H.B.; ANDRADE, V.J.; PEREIRA, C.S. et al. Estudo da curva de lactação em búfalas da raça mediterrânea e seus mestiços. Arquivo Brasileiro de Medicina Veterinária e Zootecnia, v.37, n.5, p.447-495, 1985.

HARMON, L.D.; KREIKEMEIER, K.K.; GROSS, K.L. Influence of addition of monensin to na alfafa hay diet on net portal and hepatic nutrient flux in steers. Journal of Animal Science, v.71, p.218-225, 1993.

HAYES, D.P.; PFEIFFER, D.U.; WILLIAMSON, N.B. Effect of intraruminal monensin capsules on reproductive performance and milk production of dairy cows fed pasture. Journal of Dairy Science, v.79, p.1000-1008, 1996.

HERGAZY, M.A. Influence of monensin on blood metabolite e reproductive of suckeled buffalo cows. Assiut Veterinary Medical Journal, v.36, n.72, p.313-325, 1997.

INSTITUTO ADOLFO LUTZ. Normas analíticas do Instituto Adolfo Lutz. Métodos químicos e físicos para a análise de alimentos. São Paulo: 1976. 371p. 
JORGE, A. M.; GOMES, M.F.I.V; HALT, R.C. et al. Efeito da utilização da somatrotopina bovina recombinante (BST) sobre a produção de leite de búfalas. Revista Brasileira de Zootecnia, v.31, n.3, p.1230-1234, 2002.

KAR, D.; SEGUPTA, B.P. Effect of yeast culture feeding on body weight changes, feed and water intake and feed conversion efficiency in lactating Murrah buffaloes. In: CONGRESSO MUNDIAL DE CRIADORES DE BÚFALOS, 4., 1994, São Paulo. Proceedings... São Paulo: 1994. v.2, p.184-186.

KEARL, L.C. Nutrient requirements of ruminants in developing countries. Section 10. Domestic buffalo. Logan: International Feed Institute, Uthah State University, 1982. p.89-113.

LEAN, I.J.; CURTIS, M.; DYSON, R. et al. Effects of sodium monensin on reproductive performance of dairy cattle. I Effects on conception rates, calving to conception intervals, calving to heat and milk production in dairy cows. Australian Veterinary Journal, v.71, n.9, p.273-277, 1994.

LEMENAGER. R.P.; OWENS, F.N.; LUSBY, K.S. et al. Monensin forage intake and lactation of range beef cows. Journal Animal Science, v.47, n.1, p.247-254, 1978.

PERKINS, B. L.; SMITH, R.D.; SNIFFEN, C.J. Body condition scoring: useful tool for dairy herd management. Cornell Cooperative Extension Dairy Management Fact Sheet, Ithaca: Cornell University, 1985. p.150.

RAMANZIM, M.; BAILONI, L.; SCHIAVON, S. et al. Effect of monensin on milk production and efficiency of dairy cows fed two diets differing in forage to concentrate. Journal of Dairy Science, v.80, p.1136-1142, 1997.

ROSATI, A.; Van FLECK, L.D. Genetic parameters for milk, fat, protein and Mozzarela cheese production for italian river buffalo Bubalus bubalis population. Livestock Production Science, v.74, p.185-190, 2002.

ROSI, F.; DELL' ORTO, V.; CAPALBO, R. et al. Effetto dela somatrotopina bovina ricombinante e dei saponi di calcio di acidi grassi nella bufala latte italiana. Bubalus bubalis, v.1, p.69-76, 1997.

RUIZ, R.; ALBRECHET, G.L.; TEDESCHI, L.O. et al. Effect of monensin on the performance and nitrogen utilization of lacting dairy cows consuming fresh forage. Journal of Dairy Science, v.84, p.1717-1727, 2001

RUSSEL, J.B.; STROBEL, H.J. Effect of ionophores on ruminal fermentation. Applied Envromental Microbiology, v.55, p.1-6, 1989.

UNIVERSIDADE FEDERAL DE VIÇOSA - UFV. SAEG Sistema de Análise Estatística e Genética. Viçosa, MG: 1997.

SAUER, F.D.; KRAMER, J.K.G.; CANTWELL, W.J. Antiketogenic effects of monensin in early lactation. Journal of Dairy Science, v.72, n.2, p.436-442, 1989.
STANDARD METHODS FOR THE EXAMINATION OF DAIRY PRODUCTS. American Public Healt Association. 13.ed. Washington, D.C.: 1975. 345p.

STEPHENSON, K.A.; LEAN, I.J.; HYDE, M.L. et al. Efects of monensin on the metabolism of periparturient dairy cows. Journal of Dairy Science, v.83, p.830-837, 1997.

TONHATI, H.; MUÑOZ, F.C.; OLIVEIRA, J.A. et al. Parâmetros genéticos para a produção de leite, gordura e proteína de bubalinos. Revista da Sociedade Brasileira de Zootecnia, v.29, n.6, p.2051-2056, 2000.

TONHATI, H. Produção e qualidade do leite e melhoramento genético no Estado de São Paulo, Jaboticabal: Universidade Estadual Paulista, 2001. Tese (Livre Docência) - Universidade Estadual Paulista, 2001.

VALLE, W.G. Perspectivas da bubalinocultura no Brasil e na América Latina. In: TONHATI, H.; BARNABE, V.H.; BARUSELLI, P.S. (Eds.) Bubalinos: sanidade, reprodução e produção. Jaboticabal: Universidade Estadual Paulista, 1999. p. 1-26.

VALLIMONT, J.E.; VARGA, G.A.; ARIELI, A. et al. Effects of prepartum somatotropin and monensin on metabolism and production of periparturient holstein dairy cows. Journal of Dairy Science, v.84, p.2607-2621, 2001.

VAN DER MERWE, B.J.; DRUGMORE, T.J.; WALSH, K.P. The effect of monensin on milk production, milk urea e body score condition of grazing dairy cows. South African Journal of Animal Science, v.31, n.1, p.49-55, 2001.

Van Der WERF, J.H.J.; JONKER, L.J.; OLDENBROEK, J.K. Effect of monensin on milk production by Holstein and Jersey cows. Journal of Dairy Science, v.81, p.427-433, 1998.

Van SOEST, P.J.; ROBERTSON, J.B.; LEWIS, B.A. Methods for dietary fiber, neutral detergent fiber and nonstarch polysaccharides in relation to animal nutrition. Journal of Dairy Science, v.74, n.10, p.3583-3597, 1991.

WOOD, P.D.P. Algebraic model of the lactation curve in cattle. Nature, p.164-165, 1967.

ZICARELLI, L. Nutrition of dairy buffalos. In: TONHATI, H; BARNABE, V.H.; BARUSELLI, P.S. (Eds.) Bubalinos: sanidade, reprodução e produção. Jaboticabal: Universidade Estadual Paulista, 1999. p.157-178. 